\title{
Desarrollo e hiperconsumo: la producción de lo efímero*
}

\section{Development and hyper-consumption: The production of the ephemeral}

\begin{abstract}
François-Xavier Tinel
Economista de la Facultad de Economía de la Université de Picardie Jules Verne, Amiens (Francia), Magister en Economía con mención en Economía Internacional, Moneda y Finanzas de la Facultad de Economía de la Université de Picardie Jules Verne, Amiens (Francia),

Maestría en Ciencias Sociales con mención en Relaciones Internacionales de la Facultad Latinoamericana de Ciencias Sociales (FLACSO-Ecuador). Docente-investigador Maestría en Planeación para el Desarrollo, Universidad Santo Tomás. Líder del grupo de investigación "Conflictos sociales, género y territorios". Contacto: francoistinel@usantotomas.edu.co
\end{abstract}

Artículo de reflexión

Fecha de recepción: agosto 29 de 2015 • Fecha de aprobación: septiembre 19 de 2015

Mientras no sepamos por qué y para qué la gente necesita lujos [vale decir, bienes más allá de los indispensables para la supervivencia] no estaremos tratando los problemas de desigualdad ni remotamente en serio ${ }^{1}$

\section{RESUMEN}

Este artículo examina el lugar del hiperconsumo en la sociedad moderna como representación dominante del desarrollo. Comprende el hiperconsumo como una suerte de "tipo ideal" o de ícono del desarrollo; a su vez, analiza el papel que desempeñan los "malls" como nodos centrales de esta era hiperconsumista así como el rol de la imaginería publicitaria en el proceso de reencantamiento de lo cotidiano. Finalmente, ofrece algunas reflexiones sobre las grandes transformaciones acaecidas por el desarrollo del hiperconsumo y propugna por la creación de un nuevo sistema de valores.

* Artículo de reflexión que recoge parte de las discusiones del espacio académico "Teorías y perspectivas del desarrollo humano integral” de la Maestría en Planeación para el Desarrollo de la Universidad Santo Tomás (Colombia).

1 Douglas 1998, citado en Bauman 2007, p. 47 
Palabras clave: desarrollo, hiperconsumo, felicidad, crecimiento económico.

\begin{abstract}
This article examines the place of hyper-consumption in modern society as the dominant representation of development. It understands hyper-consumption as a sort of "ideal type" or development icon; in turn, it analyzes the role of "malls" as central nodes of this hyperconsumerist era and the role of advertising imagery in the process of re-enchantment of everyday life. Finally, it offers some reflections on the great transformations occurred due to the development of hyper-consumption and calls for the creation of a new value system.
\end{abstract}

Keywords: Development, hyper-consumption, happiness, economic growth.

El consumo es un acto natural, inherente a la vida misma porque es fundamental para la reproducción de nuestra propia existencia. Así, de acuerdo con Lara González (2009, p. 1) "consumimos antes de nacer, desde el vientre materno estamos consumiendo a la vez que generamos materiales de desecho o residuales en el proceso". Empero, el consumo, tal como lo entendemos en nuestro medio, debe comprenderse en el contexto de la moderna sociedad postindustrial, ya no solo como un medio para la satisfacción de necesidades básicas sino también como una herramienta de la diferenciación social (Veblen, 1974; Bourdieu, 1979). Los objetos de consumo no responden solamente a fines prácticos, satisfaciendo necesidades individuales, también obedecen a otra lógica: la del valor signo, la de la diferencia (Baudrillard, 1976). Reconocer lo anterior constituye grosso modo un punto de partida esencial para quien quiera estudiar la problemática del consumo en nuestra "modernidad líquida” (Bauman, 2008), marcada por la transitoriedad y volatilidad de los vínculos humanos.

Sin embargo, vale aclarar la diferencia entre consumo y consumismo ya que, a diferencia del primero que sustancialmente cumple funciones esenciales para la supervivencia humana, el segundo estaría más asociado a la satisfacción del deseo: 
(...) en franca oposición a anteriores formas de vida, no asocia tanto la felicidad con la gratificación de los deseos (...) sino con un aumento permanente del volumen y la intensidad de los deseos, lo que a su vez desencadena el reemplazo inmediato de los objetos pensados para satisfacerlo y de los que se espera satisfacción (Bauman, 2007, p. 50).

Creemos que ahí se encuentra el meollo de la sociedad del hiperconsumo e incluso de la concepción occidental del desarrollo. Es así que dentro de las representaciones sociales dominantes del desarrollo, el consumo, o más precisamente, el hiperconsumo ocupa un lugar particular y digno de interés. No es azar que una de las principales perspectivas ortodoxas del desarrollo, como es la de Rostow (1974), reconozca en el consumo de masa la última etapa del desarrollo. Esta fase se presenta como el cumplimiento de todo el proceso de desarrollo de un país, en la cual el hombre se realiza a través la actividad de consumo de bienes y servicios duraderos, alcanzando un nivel de bienestar mucho mayor que en las fases iníciales. El consumo, y más tarde, el hiperconsumo adquirieron una justificación ética para convertirse paulatinamente en el fin último del desarrollo.

Por ende, este artículo pretende analizar la forma en que el hiperconsumo (Lipovetsky, 2006) se ha construido en un parámetro hegemónico de desarrollo, como la cristalización misma de lo que representa una sociedad desarrollada, casi universalmente reconocida aunque se debe anotar que existen resistencias glocales y modos de vida alternativos a los que apunta la moderna sociedad de consumidores. Esto nos llevará a entender, por un lado, el juego de imbricaciones entre los conceptos de desarrollo y de hiperconsumo y, por otro, algunos de los pilares que lo sustentan. Si se compara con temáticas como el estudio de la democracia, las migraciones internacionales o aún la globalización, el interés académico en las ciencias sociales por el tema del hiperconsumo ha sido muy débil; ello porque, de alguna manera, pone en tela de juicio la representación moderna y occidental de la felicidad tal como se ha construido en la sociedad de consumidores y, peor aún, en nuestros ideales de progreso y desarrollo. 


\section{"SIN HIPERCONSUMO NO HAY DESARROLLO"}

El desarrollo es un concepto complejo, de naturaleza polisémica, que surge en el período de la postguerra en Occidente y se encuentra asociado a una serie de "significaciones sociales imaginarias" occidentales (Castoriadis, 1991); sin duda, una de ellas es el crecimiento económico. Así, de manera recurrente en las teorías económicas del desarrollo, desde sus orígenes a través de la teoría de la modernización (Rostow, 1974) hasta comprensiones más contemporáneas, como la lectura ortodoxa de la pobreza de Sachs (2007), se afirma que el crecimiento económico constituye una condición preliminar esencial para el desarrollo de una nación, e incluso, su pilar central $^{2}$. No obstante, esta relación de dependencia que entretienen las sociedades occidentales con el crecimiento económico ha sido criticada de manera vehemente por los ideólogos del decrecimiento (Ariès, 2008; Latouche, 2004, 2008); estos ponen de relieve que el crecimiento económico se ha convertido en el único régimen de verdad de la modernidad occidental, tal como si fuese la "cura milagrosa" a una serie de problemas de orden socioeconómico. Por ejemplo, cuando se avecina una crisis, una de las estrategias más optadas para estimular el crecimiento económico se materializa en reactivar el consumo ${ }^{3}$.

Históricamente, el tríptico que articula desarrollo, crecimiento económico y consumo de masa toma sus raíces en el trabajo de Rostow (1974) quien, con base

2 Históricamente, el hecho de que la idea de crecimiento ocupe tanta importancia en la ciencia económica e incluso en nuestras propias existencias no es anodino, refleja una revolución en el sistema de valores, una ruptura con el pasado. Esta ruptura emerge con el pensamiento liberal que nace en Europa occidental a fines del siglo XVIII; se traduce por el retroceso de lo religioso y lo político en beneficio de lo económico. La economía se convierte paulatinamente en una ciencia de la riqueza (Rosanvallon, 1999) al haberse liberado de la moral y de la política (Dumont, 1999). En otras palabras, la economía se presenta desde ese entonces como el campo de los posibles, como el ámbito en el cual se pueden plasmar todos los ideales de progreso y desarrollo. Sin embargo, esta creencia en el crecimiento, como fundamento principal del desarrollo, empezó a ser criticada por doquier muy prontamente ya que no contemplaba más que el crecimiento por el crecimiento, como un fin en sí mismo (Castoriadis, 1991; Latouche, 2004, 2008). Así, en palabras de Rist (2002, p. 58), "si el motor del "desarrollo" es el crecimiento, el motor del crecimiento es la creencia y falta mucho para que sea compartida por todos".

3 Ver artículo de Nicolas Bourcier "Rattrapé par la crise, le Brésil veut stimuler sa consommation" (Atrapado por la crisis, Brasil quiere estimular el consumo, traducción del autor), Le Monde, 14-05-2013. Disponible en http://www.lemonde.fr/bresil/article/2013/05/14/rattrape-par-la-crise-le-bresil-veut-stimuler-saconsommation_1841814_1666636.html 
en el análisis de las condiciones históricas del desarrollo económico de los países de Europa occidental, Japón y Estados Unidos, establece que existe una serie de patrones comunes de crecimiento, clasificables en cinco etapas: la "sociedad tradicional", las "condiciones previas para el despegue", el "despegue (take off), la "marcha hacia la madurez" y, finalmente, la "era de alto consumo de masas". La era del consumo de masas puede estar asociada a la de la sociedad de consumo, es decir a la de una sociedad en la que los consumidores están estimulados para consumir de manera abundante. La sociedad de consumo sería el estado último de evolución de las sociedades; en este estado se encontrarían los llamados "países desarrollados"; a diferencia, los países emergentes o "en desarrollo" estarían entonces en camino hacia esta etapa final. En este sentido, el trabajo de Rostow se presenta como una piedra angular de la doctrina que afirma que el consumo constituye un mecanismo eficiente para alcanzar y sostener el crecimiento económico de una nación y, por ende, es el principal medio para su desarrollo.

No obstante, de acuerdo con Lipovetsky (2006), más que encontrarnos en una sociedad de consumo de masas, que caracterizó a la mayoría de los países occidentales entre los ańos cincuenta y setenta, la globalización económica asociada a un proyecto cultural de occidentalización del mundo (Latouche, 1989) abrió la puerta de una nueva era, la del hiperconsumo como última fase de un capitalismo de consumo. Ello correspondería a la sexta etapa del ciclo de Rostow; dicha etapa se diferencia de la anterior, no por el principio de masificación de la producción y del consumo de mercancías que recoge de la sociedad de consumo de masas sino por el ritmo acelerado de desarrollo de estos procesos.

Además, se debe resaltar que el "hiperconsumo" (Lipovetsky, 2006), aún llamado "consumismo" (Bauman, 2007), surge como una fuerza sistémica que "coordina (...) la integración social, la estratificación social y la formación del individuo humano" (Bauman, 2007, p 47); por tanto, el consumo de la modernidad liquida logró desplazar el rol articulador que cumplía el trabajo en la sociedad de productores de la modernidad sólida (Bauman, 2007).

A su vez, el hecho de que los modelos de desarrollo económico contemporáneos de las sociedades occidentales dependan en gran parte de la capacidad de los individuos 
para desprenderse de su dinero, se ha dado en un contexto particular en el que el tiempo fue adquiriendo nuevos significados. La urgencia y la instantaneidad llegaron a ser las nuevas medidas del tiempo en el contexto de la globalización económica y financiera y del desarrollo de las nuevas tecnologías (Aubert, 2009); por ende, en este contexto de la inmediatez, la vida adquiere un nuevo sentido ya que "(...) no es más que un encadenamiento de presentes, una colección de instantes vividos con variada intensidad" (Maffesoli, 2000, citado en Bauman, 2007, p. 53).

La reinterpretación de la noción de tiempo en la modernidad líquida así como la creencia predominante en el crecimiento económico que invita a mantener altos niveles de consumo o a acelerarlos, reenvía a otra problemática fundamental para poder comprender la crisis del modelo de desarrollo hegemónico del productivismo y del consumismo: la del hubris del ser humano (Latouche, 2004), la desmesura en sus relaciones con la naturaleza. De alguna forma, las recurrentes crisis financieras y económicas, así como la crisis ecológica cada vez más visible, conllevan a afirmar que la economía mundial estaría gobernada actualmente por dos ideas: la inmediatez y el exceso. Así, según Bauman (2007):

La economía consumista medra con el movimiento de bienes, y cuanto más dinero cambia de mano tanto más florece. Y cada vez que hay dinero que cambia de mano hay productos de consumo que van a parar a la basura. Por lo tanto, en una sociedad de consumidores la búsqueda de la felicidad -el propósito invocado con más frecuencia y utilizado como carnada en las campańas publicitarias destinadas a atizar el deseo de los consumidores de desprenderse de su dinero (dinero ganado o dinero que uno espera ganar)- pasa de estar enfocada en producir cosas o apropiárselas (ni hablar de almacenarlas) para enfocarse en su eliminación: justo lo que necesita un país cuyo producto bruto está en baja. Para esta economía, aquella búsqueda anterior, hoy dejada de lado, por completo, era portadora de los peores presagios: estancamiento, suspensión y decaimiento del fervor consumista. La nueva orientación, sin embargo, resulta un buen signo: una ronda de compras más. Si la urgente necesidad de adquirir y poseer no se complementase con la de eliminar y descartar se transformaría en un problema de almacenamiento a futuro (p. 58). 
En efecto, pese al carácter finito del mundo, la globalización económica, a través de la sociedad del hiperconsumo, brinda una infinidad de bienes consumibles e incluso estilos de vida por consumir; por ende, el mito de la abundancia y del derroche llega a convertirse en un potente sustento para el florecimiento de la economía e incluso para su propia supervivencia. En este sentido, mientras permanezca la creencia de que "más" es sinónimo de mejor, mientras el consumidor sea sometido al "yugo hedonista" (Layard, 2005 citado por Bauman, 2007, p. 69) y mientras no logre superarse esta fe ciega en el crecimiento económico, incluso para los que abogan por un crecimiento sostenido o un crecimiento verde, el modelo de desarrollo dominante seguirá articulado alrededor de esta cultura del hubris. Es esencial reiterar que esta noción de hubris cristaliza la crisis sistémica y civilizatoria que vivimos, la cual no solo se limita a una crisis económica, también tiene aristas políticas, ecológicas y sociales (Viveret, 2010); en pocas palabras, se trata de una crisis del modelo de consumo (Moati, 2009). En efecto, dentro de la nueva agenda del desarrollo que plantea los ODS (Objetivos del desarrollo sostenible) de las Naciones Unidas para los próximos quince años, 2015-2030, uno de los objetivos que atañe a modalidades de producción y consumo sostenible se centra en la necesaria regulación del consumo energético y la disminución de la generación de desechos a nivel global; empero, no se alcanza a plantear metas claras que se refieren explícitamente a esta práctica del sobreconsumo ya que solamente se contempla que, para el año 2030, "las personas de todo el mundo tengan información y conocimientos pertinentes para el desarrollo sostenible y los estilos de vida en armonía con la naturaleza" (Naciones Unidas, 2015). Ello es distinto a afirmar que la humanidad tiene "la obligación económica, ecológica, política y moral” de limitar su consumo (Viveret, 2010) y que requiere una transformación profunda de sus modos de vida.

"Sin hiperconsumo no hay desarrollo" constituye una afirmación un tanto provocadora pero que, en muchos aspectos, cristaliza las dinámicas contemporáneas de la economía globalizada. Entender cómo la lógica del desarrollismo se sustenta en parte en el hiperconsumo nos lleva también a observar dos de sus principales pilares centrales que validan esta cultura consumista. Por un lado, a través de una de sus figuras centrales: los malls que operan como nodos centrales de la sociedad del hiperconsumo; por otro, mediante el análisis del papel que juega la publicidad para alimentar estas tendencias del sobreconsumo. 
Campos en Ciencias Sociales

El desarrollo desde sus perspectivas multidisciplinar y transdisciplinar

\section{EL HIPERCONSUMO: REENCANTANDO EL MUNDO}

El hecho de que florezcan los centros comerciales dentro del paisaje urbano y que sean concurridos de forma masiva, revela la relación que entretienen las personas con el hiperconsumo. Por ejemplo, en Colombia, según proyecciones de la Asociación Nacional de Centros Comerciales, se contempla la apertura de un centro comercial (mall) cada 20 días para el año 2018 (El Tiempo, 2015). Sin embargo, los centros comerciales son más que edificios comunes, funcionan como lugares sagrados (Pahl, 2009) $)^{4}$ y retomando la terminología de Ritzer (2000) podrían calificarse como "catedrales del consumo". Al ser herméticos al mundo exterior, representan unas oasis de paz y tranquilidad para las personas que se refugian en ellos. Así, gracias a una estética que invita a perderse mediante una serie "(...) de recovecos y de pasajes inesperados" (Caro, 2015, p. 18), el individuo, solo o junto con los suyos, puede abandonarse al disfrute de la experiencia consumista frente al carácter angustiante e incierto de la realidad exterior. Como lo relata Bauman (2008, p. 106), "el templo del consumo, bien supervisado, vigilado y protegido, es una isla de orden, libre de mendigos, saqueadores, vagos y merodeadores (...)".

Retomando los aportes de Lara González (2009, p. 3) señala que el centro comercial (mall) "(...) olvida lo que lo rodea: no solo cierra su recinto a las vistas de afuera sino que irrumpe en una manzana de la ciudad a la que ignora”. En efecto, en estos espacios han desaparecido todos los referentes espacio-temporales de tal forma que el shopping se convierta en una aventura colorida y segura. Ahí, el consumidor puede

4 Según Pahl (2009) la simbólica religiosa permea los espacios del hiperconsumo como lo son los centros comerciales. En ellos, el agua está presente en casi todos mediante cascadas, fuentes, chorros para acompañar a la gente en la liquidez de la experiencia consumista; todo está hecho para recordar el simbolismo religioso: el agua que purifica. Sus creadores incluyeron este concepto de manera muy astuta, somos hechos de agua y no podemos vivir sin agua; el agua es fuente de vida y la presencia del agua nos invita a "volver a nacer". Este lugar se convierte así en un espacio idóneo que ofrece “(...) una multitud de nuevos comienzos y resurrecciones” (Bauman, 2007, p. 73). Lo mismo pasa con el uso de la luz, la cual representa la energía y la vida. Es por esto que muchos centros comerciales han incorporado en su diseño arquitectónico pozos de luz con el fin de reconocer este lugar como un lugar aparte. Tienen techos muy altos de tal manera que el comprador tenga la sensación de estar como en un templo y se sienta muy pequeño frente a la grandeza de la obra. Finalmente, la presencia de matas y arboles no es anodina, reenvía a la idea de un lugar donde podemos crecer, donde podemos ser alguien y vivir eternamente (Pahl, 2009); de alguna forma, es una promesa de seguridad. 
buscar, explorar y adquirir los productos que luego expondrá en las calles (Bauman, 2006, p. 80).

De igual manera, la terminología atribuida a los centros comerciales nos interpela sobre el tipo imaginario consumista que pretenden construir y la función que pretenden asumir, como nuevos lugares de encuentro con los demás e incluso consigo mismo. Pasaron de ser unos "no lugares" de acuerdo con Augé (2000), a saber como meros espacios de tránsito en donde fluyen personas, mercancías y dinero, a nuevos escenarios de aculturación y de religación social (Caro, 2015). En este sentido, el nombre de "El Retiro", centro comercial de la ciudad de Bogotá, no es anodino. La palabra "retiro" invita a apartarse del mundo exterior o aún se refiere a un ejercicio piadoso de aislamiento para rezar y reflexionar sobre su propia existencia; en este caso, la palabra reenvía a la imagen de un refugio frente a la realidad inquietante del mundo exterior para abandonarse al deleite de una ronda de compras o para disfrutar de las actividades de recreación que ofrece el lugar.

De acuerdo con Lipovetsky (2006), el hiperconsumo funciona cada vez menos según el modelo de enfrentamientos simbólicos, como los de la distinción social (Bourdieu, 1979), entre otros, para obedecer más a una lógica emotiva y hedonista que permite que el individuo consuma primero para dar $(\mathrm{se})^{5}$ placer $^{6}$, más que para rivalizar con otro. Esta búsqueda de reconocimiento identitario mediante el consumo, y ya no tanto estatutario como antes, refleja una época en la que las tradiciones, la religión y la política son menos productoras de identidad social que antaño. Así, como lo expresa Lipovetsky (2006)

No encuentro término más idóneo que el de hiperconsumo para dar cuenta de una época en la que los gastos no tienen más por motor el reto, la diferencia, los enfrentamientos simbólicos entre los hombres. Cuando las luchas competitivas no son más la clave de bóveda de las adquisiciones mercantiles,

5 La lógica del consumo se inscribe también en la del don; en efecto, se consume para dar, a los demás o así mismo (Caillé, Chanial, Coval \& Rémy, 2014).

6 Muchos de los lemas publicitarios juegan con esa aspiración de felicidad y proponen nuevas experiencias de vida, de placer. Según Lipovetsky (2006, p. 39), “(...) la publicidad y los medias exaltan el disfrute-minuto enseñando por doquier los sueńos de eros, comodidad y ocios”. 
empieza la civilización del hiperconsumo, este imperio en el que el sol de la mercancía y del individualismo extremo no se acuesta nunca. (...) El consumo "para sî" suplantó el consumo "para el otro" en relación con el irresistible movimiento de la individualización de las expectativas, de los gustos y de los comportamientos $^{7}$ (pp. 45-46).

Esta lógica moderna del disfrute de nuevas experiencias de placer ha sido posible a través de un doble movimiento: el de la "democratización del deseo" (Lipovetsky, 2006, p. 33) junto con la liberación de las barreras emocionales y morales de la pulsión y del deseo (Lipovetsky, 2006; Bauman, 2007). Así, “al transformar los lugares de ventas en palacios de ensueño, los grandes almacenes han revolucionado nuestra relación al consumo" (Lipovetsky, 2006, p. 33); se esfuerzan por estimular los deseos de consumir, fomentar el deseo por lo nuevo y la moda mediante astutas estrategias de mercadeo. Existe una teatralización de los puntos de venta en tanto "lo que se vende no son únicamente productos, sino todo un espacio temático cuya vocación es la de contribuir a que los consumidores tengan un poco de sueńos, escapen a su rutina" ${ }^{8}$ (Hetzel, 2002, p. 90). Hetzel explica que el "marketing experiencial" debe responder a deseos existenciales del consumidor actual ${ }^{9}$. Hay una suerte de "reencantamiento" de lo cotidiano gracias a experiencias de consumo extraordinarias en las cuales los consumidores están inmersos; por ende, el consumo alcanza a provocar "sensaciones y emociones que, lejos de responder solamente a necesidades, logran responder hasta a la búsqueda identitaria del consumidor” (Hetzel, 2002).

Se encuentra en juego una sacralización de lo profano en la experiencia de consumo (Baudrillard, 2011). El simple producto o servicio consumible está escenificado para alcanzar una dimensión sagrada. En este sentido, según Lipovetzsky (2006), el reencantamiento de lo cotidiano no pasaría únicamente por una multiplicación de microplaceres que ofrecería la experiencia de consumo; más fundamentalmente,

7 Traducción del autor. Todas las citas de Lipovetsky (2006) han sido traducidas por el autor.

8 Traducción del autor.

9 Según Lipovetsky (2006, p. 48), “a diferencia del marketing tradicional que ponía de relieve argumentos racionales y la dimensión funcional de productos, muchas marcas le apostan a la sensorialidad y al afecto, a las "raíces" y a la nostalgia (el "retromarketing"). Otras insisten en los mitos o en lo lúdico. Otros aún reavivan el sentimiento ciudadano, ecológico (...)”. 
se inscribiría en tentativas de inmersión del consumidor en experiencias que le permitirían dar sentido a su propia existencia. Se asiste a una expansión del mercado del alma y a su transformación por lo que la pregunta de la "felicidad interior" se convierte en un segmento comercial, un objeto de marketing que el consumidor quiera adquirir.

Lo que está en venta no solo es un producto o un servicio, es un imaginario, es decir un concepto sagrado: la belleza, la juventud, la seducción, la felicidad. Por tanto, el consumo tiene que ver cada vez más con una experiencia de sí, mediante la búsqueda de felicidades individuales, de "salud ilimitada" y de optimización de los medios corporales y relacionales. Así, el consumo asume una función existencial mediante la búsqueda personalizada de sentidos. En efecto, los productos están cargados de sentido gracias a toda la publicidad que se genera en su alrededor. Heilbrum (2010) asimila la marca a una suerte de "ícono cultural y religioso"; la función de una marca sería la de "fortalecer o modificar los sistemas de creencia existentes (...), se ha convertido finalmente en una esfera de autoridad al proponer modos de consumo, de pensamiento y por ende de vida” (Heilbrum, 2010, pp. 120-121). Es así que las marcas contribuyen, por la fuerza de sus discursos, a modificar la relación del individuo con el mundo, con su cuerpo y con los demás, de tal forma que imponen nuevos parámetros identitarios para mirarse a sí mismo y a los demás.

Históricamente, lo anterior se posibilitó, por un lado, gracias a la "democratización del deseo" (Lipovetsky, 2006, p. 33) y, por otro, mediante su renovación constante. El "amor por lo nuevo" es una característica de las sociedades occidentales y responde al apetito del consumidor por probar nuevas experiencias. Este "consumo emocional" como lo define Lipovetsky (2006, p. 49) marca la victoria del ser sobre el parecer; lo que importa es tener una imagen positiva de sí mismo (Lipovetsky, 2006, p. 51). Empero, se daría una lectura errónea al decir que la sociedad del hiperconsumo descansa únicamente en la creación de nuevos deseos; en efecto, el pilar principal de la sociedad de consumo no se encuentra tanto en la creación de nuevos deseos como en la frustración de los deseos creados, frustración que se genera posteriormente (o 
simultáneamente) al acto de compra y que se asocia con un sentimiento de culpa ${ }^{10}$, el cual podría llegar a ser calmado por otra ronda de compras.

También, es importante observar que la publicidad no solo insiste en el carácter fácil, liviano, innovador y moderno de un producto sino que presenta el hecho de consumir como un acto de abandono total, libre de culpas. Los publicistas retomaron hábilmente la imagen (transformada) del Jardín de Edén en el que dejarse tentar ya no es fuente de culpa ${ }^{11}$, remordimiento y pecado, sino de placer inmediato y realización personal. La pulsión y el deseo, liberados de las barreras emocionales y morales, pueden ser satisfechos por la facilidad que representan las compras on line o aún gracias a ciertos medios de pago como las tarjetas de crédito que permiten comprar tiempo, el tiempo del trabajo y del ahorro, para satisfacer un deseo inmediato.

De la misma manera, existe una gran cantidad de publicidades que desarrollan una verdadera red de significaciones simbólicas, como lo sostienen Lugrin y Molla (2008):

Estas últimas recurren a la historia, la literatura, el arte, los grandes mitos, las ideas humanitarias, las creencias y las religiones para atraer la atención de un público en búsqueda de sentido y no solo de consumo. Estas publicidades no buscan solamente vender un producto, sino también construir sentido (p. 14).

De acuerdo con los autores, es porque la sociedad no está totalmente marcada por la cultura del cristianismo que los referentes a su historia, su pensamiento y sus imágenes se han hecho posibles. Es muy común que la publicidad deforme lo que cita, jugando con la parodia, el humor y el doble sentido (Lugrin y Molla, 2008,

10 Existen mecanismos que buscan borrar, directo o indirectamente, este sentimiento de culpa, este malestar de consumir frenéticamente. El "impuesto verde" en Chile o la "taxe carbone" en Francia son, entre otros, un ejemplo de impuestos en los que se incorpora en el precio final del producto parte del costo de su eliminación o de su reciclaje: a nivel medioambiental contribuye a borrar los desechos del producto, a nivel personal ayuda a borrar la culpa. De igual manera, las compañías comprendieron que dar un sello verde o ético a un producto (lo que se llama el Greenwashing) o incluso ponerlo en un empaque amigable con el medioambiente permite dar mayor crédito al objeto o servicio que se compra, permite, de cierta manera, re-humanizar el acto de comprar como si fuese una acto ciudadano. Según Bauman (2007, p. 59), "borrar este estigma es condición para la nueva felicidad (...)".

11 Gaillard (2008) reconoce en la culpa, ligada al pecado original, uno de los mitos fundadores del cristianismo. 
p. 20). Por ejemplo, la palabra ángel viene del latín ángelus y significa mensajero de Dios; su uso publicitario tendería a demostrar que el producto tiene un carácter divino, o por lo menos sobrenatural.

Existe una dualidad ambivalente entre el carácter divino y tentador del producto, un acercamiento de los horizontes escatológicos creados alrededor del producto, las antinomias ángel/demonio se reconcilian para fusionarse en una sola figura como el perfume "ángel o demonio" de Nina Ricci que juega con las ambivalencias, a la vez angélico y diabólico. En esta fórmula, hay un acercamiento de la idea de paraíso y de infierno, bajo el supuesto de que el paraíso no sería más que el lugar de la satisfacción de todos nuestros deseos, nuestras pulsiones y nuestros pecados. Ángeles y demonios son complementarios y ocupan lugares intercambiables. Así, de acuerdo con Lugrin y Molla (2008):

La publicidad contemporánea parece reflejar una sociedad donde el diablo, a escoger, es preferido al ángel, encarnando el rechazo de las leyes, la libertad, el éxito social, la expresión del individualismo... Si el diablo se ha angelizado, a diferencia el ángel se ha pervertido (...) Así a la ya ambivalencia del ángel se opone el angelismo del diablo. No se trata solamente de una nivelación ángel/demonio, sino incluso a veces de una inversión: si tuviéramos que escoger, preferiríamos ser un demonio que un ángel. No es un azar si ángeles y demonios reciben rasgos y atributos (sexo) fundamentalmente humanos: favorecen la identificación del consumidor (p. 43).

Ángeles y demonios, Adán y Eva, serpiente y manzana, todos se invitan en las propagandas publicitarias. Si bien es el texto bíblico el que funda estas múltiples representaciones, cabe señalar que las temáticas del "Bien" y del "Mal" y de la tentación permanecen en el corazón de las preocupaciones actuales. De alguna forma, ceder a la tentación, liberarse del yugo de la religión y definir sus propias reglas tendería hoy a ser valorizado.

Así, el consumo se ha convertido en una actividad de producción de significaciones y de intercambios simbólicos; los consumidores no solo consumen un producto sino el sentido que carga en sí (Baudrillard, 2011; Lipovetsky, 2006; Bauman, 2007). Ello 
demuestra que nuestras pulsiones consumistas están gobernadas por el mito de la abundancia "(...) dispensada por una instancia mitológica benéfica de la cual somos los herederos legítimos: la Técnica, el Progreso, el Crecimiento, etc.” (Baudrillard, 2011, p. 29).

El paradigma del hiperconsumo expuesto por Lipovetsky (2006) converge con los planteamientos de Baudrillard y pone de relieve una característica fundamental de los "tiempos hipermodernos" (Lipovetsky y Charles, 2006), a saber una radicalización de la lógica individualista y hedonista a todo el cuerpo social en su conjunto. La mentalidad del homo consumericus ha alcanzado el orden no-económico de la familia, la religión, la escuela, la procreación, entre otros.

Frente a un futuro incierto y amenazador (precariedad, desempleo, fragilidad de los vínculos humanos...), la sociedad del hiperconsumo ofrece instantes momentáneos de tranquilidad y felicidad. Lipovestky (2006) habla de "felicidad paradójica” para explicar el hecho de que la sociedad de hiperconsumo pone de relieve incesantemente imágenes de felicidad, de bienestar por oposición a la realidad estresante y triste de nuestra sociedad.

\section{TiEMPOS EFÍMEROS}

El desarrollo parece ser, más que nunca en nuestra historia, un ideal efímero, bajo la forma hegemónica en la que está construido en nuestra modernidad occidental, es decir bajo los rasgos del crecimiento económico y del hiperconsumo. Si bien ha permitido sustentar, en algunas partes del mundo, los ideales de progreso y bienestar a los que aspira la humanidad; en muchas otras, sigue siendo productor de desigualdades, hambre y pobreza. El mito de la abundancia que está en su corazón debe ser derribado de su pedestal. Existe una conciencia global sobre el hecho de que dicho modelo hegemónico de desarrollo y crecimiento ya está mostrando sus límites si se mira la huella ecológica actual de los países de Europa occidental y Estados Unidos, es decir la presión que estos países ejercen sobre los recursos naturales y la capacidad de la tierra para autogenerarse. No obstante, es fundamental observar otros tipos de huellas que genera este modelo, de orden social, económico, cultural 
y, en general, humano. En este sentido, cada vez es mayor el consenso acerca de que el modelo de consumo occidental, más aún si debe extenderse a las poblaciones de los países emergentes o llamados "países en desarrollo", es insostenible a medio y largo plazo.

A su vez, se debe resaltar que el hiperconsumo está ligado a lo efímero (Lipovetsky, 2006), es decir que ofrece satisfacciones al mismo tiempo que crea frustraciones, sin embargo, se relaciona con lo efímero en otra dimensión. En efecto se trata de un sistema que reposa sobre la obsolescencia programada de los objetos, la cual se ve acelerada por la publicidad que crea el deseo por lo nuevo. De acuerdo con Petrella (1997, citado en Bauman, 1999, p. 104), “la globalización arrastra las economías a la producción de lo efímero, lo volátil (mediante una reducción masiva y generalizada del tiempo de vida útil de productos y servicios) y lo precario (trabajos temporarios, flexibles, de tiempo parcial)". En resumen, liquidez, velocidad y movilidad podrían ser las características de nuestras existencias globalizadas, características de una existencia posmoderna que no solo rompe con las instituciones de una primera modernidad (Beck, 2008) como la familia y la religión sino que también las reconfigura. Es así que, si bien antes las instituciones religiosas operaban como referentes estructurales de nuestra existencia, el hiperconsumo parece tender asumir este rol de ligación social, hoy en día, en sociedades en las que la gente vive situaciones complejas: crisis económicas, depresiones, desmantelamiento del núcleo familiar, etc.

Toda la fuerza de la sociedad de consumidores reside en su discurso que legítima la búsqueda hedonista, la búsqueda de placer. Crea una carrera contra el tiempo con el sentimiento que el individuo no se realiza a sí mismo, que no logra su vida si no la vive al máximo en esta maximización de todos los placeres posibles y alcanzables. Al generar una inversión personal en la búsqueda constante de la felicidad individual, la sociedad del hiperconsumo ha logrado colonizar en parte el imaginario del individuo moderno, sus formas de pensar y modos de vida.

El encontrarnos en una encrucijada de nuestra historia, se invita a generar una toma de conciencia tanto individual como colectiva del retorno indispensable de la moral y de la ética en nuestras vidas, es decir de la primacía del ser humano y de la naturaleza sobre las demás cosas materiales. Latouche $(2004$, p. 88$)$ expresa que 
no se trata de culpabilizar a los consumidores para convertirlos al ascetismo, sino de responsabilizarlos como ciudadanos.

\section{REFERENCIAS}

Ariès, P. (2008). La Décroissance: un nouveau projet politique. Villeurbane: Edtions Golias.

Aubert, N. (2009). Le culte de l'urgence. La société malade du temps. Paris: Flammarion.

Augé, M. (2000). Los “no lugares” espacios del anonimato. Una antropología de la sobremodernidad. Barcelona: Gedisa Editorial.

Baudrillard, J. (2011). La société de consommation. Paris: Folio essais

Baudrillard, J. (1976). La génesis ideológica de las necesidades. Barcelona: Anagrama.

Bauman, Z. (2008). Modernidad liquida. México: FCE.

Bauman, Z. (2007). Vida de consumo. Buenos Aires: FCE.

Beck, U. (2008). ¿Qué es la globalización? Falacias del globalismo. Respuestas de la globalidad. Barcelona: Paidós.

Bourdieu, P. (1979). La distinction: critique sociale du jugement. Paris: Les Editions de Minuit.

Caillé, A.; Chanial, P.; Coval, B. \& Rémy, E. (2014). "Présentation. Consommer, donner, s'adonner. Les resorts de la consommation”. Revue du MAUSS, (44) pp. 5-24.

Caro, A. (2015). "El mal como mecanismo de aculturación”. En Alter nativas. Revista de estudios culturales latinoamericanos. Recuperado de http://alternativas.osu.edu/es/issues/ spring-4-2015/essays/caro.html 
Castoriadis, C. (1991). “Reflexiones sobre el 'desarrollo' y la 'racionalidad'. En F. Giraldo y F. Viviescas (Comps.) Colombia: el despertar de la modernidad. Foro Nacional por Colombia, Bogotá. [En línea]. Recuperado de http://www.fundanin.org/castoriadis7.htm

Dumont, L. (1999). Homo aequalis. Génesis y apogeo de la ideología económica. Madrid: Taurus.

El Tiempo (2015). Al 2018 cada 20 días se inaugurará un centro comercial en el país. Urbanización y modernización del comercio, algunas causas que impulsan a los constructores. [En línea]. Recuperado de http:/www.eltiempo.com/economia/sectores/ centros-comerciales-en-colombia/16022477

Gaillard, A. (2008). Les mythes du christianisme. Paris: Editions Publibook.

Heilbrum, B. (2010). Que sais-je? (255). La marque. Paris: PUF

Hetzel, P. (2002). Planète conso. Markéting expérentiel et nouveaux univers de consommation. Paris: Editions d'Organisation

Lara González, D. J. (2009). “Consumo y consumismo. Algunos elementos traza sobre estudiantes universitarios en México". En Nómadas. Revista Crítica de Ciencias Sociales y Jurídicas, $\mathrm{N}^{\circ} 21$ (2009.1). Madrid: Universidad Complutense. [En línea]. Recuperado de http://pendientedemigracion.ucm.es/info/nomadas/21/davidlara.pdf

Latouche, S. (2008). La apuesta por el decrecimiento: ¿Cómo salir del imaginario dominante? Barcelona: Icaria

Latouche, S. (2004). Petit traité de la décroissance sereine. Paris: Editions Milles et Une Nuits.

Latouche, S. (1989). L'occidentalisation du monde. Essai sur la signification, la portée et les limites de l'uniformisation planétaire. Paris: La Découverte.

Lipovetsky, G. (2006). Le bonheur paradoxal. Essai sur la société d'hyperconsommation. Paris: Gallimard. 
Lipovetsky, G. y Charles, S. (2006). Les temps hypermodernes. Paris: Lgf

Lugrin, G. y Molla, S. (2008). Dieu, otage de la pub? Paris: Labor et Fides.

Moati, P. (2009). "Cette crise est aussi celle de la consommation". En Les Temps modernes, No655 (4/2009), pp. 145-169.

Naciones Unidas. (2015). Objetivos de desarrollo sostenible. 17 objetivos para transformar nuestro mundo. [En línea]. Recuperado de http://www.un.org/sustainabledevelopment/es/

Pahl, J. (2009). Shopping Malls and Others Sacred Places: Putting God in Place. Eugene: Wipf and Stock Publishers

Rist, G. (2002). El desarrollo: historia de una creencia occidental. Madrid: Catarata.

Ritzer, G. (2000). El encanto de un mundo desencantado: revolución en los medios de consumo. Barcelona: Ariel.

Rosanvallon, P. (1999). El capitalismo utópico. Buenos Aires: Ediciones Nueva Visión.

Rostow, W.W. (1974). Las etapas del crecimiento económico. Un manifiesto no comunista. México: FCE.

Sachs, J. (2007). El fin de la pobreza. ¿Cómo conseguirlo en nuestro tiempo? Bogotá: DeBolsillo.

Veblen, T. (1974). Teoría de la clase ociosa. México: FCE.

Viveret, P. (2010). «Sortir de la démesure.», Revue Projet (317), pp. 13-19 